\title{
Morphology and Damping Behavior of Polyurethane/PMMA
}

\section{Simultaneous Interpenetrating Networks}

\author{
S.H. Wang ${ }^{\mathrm{a}}$, S. Zawadzki ${ }^{\mathrm{b}}$ L. Akcelrud ${ }^{\mathrm{b}}$ \\ ${ }^{a}$ Escola Politécnica da Universidade de São Paulo, Departamento de Engenharia \\ Metalúrgica e de Materiais, 05508-900 São Paulo - SP, Brazil \\ ${ }^{\mathrm{b}}$ Departamento de Química, Universidade Federal do Paraná, Centro Politécnico, \\ 81531-990 Curitiba - PR, Brazil
}

Received: November 14, 2000; Revised: January 19, 2001

\begin{abstract}
A series of polyurethane/PMMA simultaneous interpenetrating networks (SINs) with various hard segment contents $(\mathbf{X})$ in the polyurethane phase (X=15.5 to $36.5 \%$ in polyurethane $)$ and wide range of polyurethane (PU) to polyacrylate $(\mathrm{PA})$ ratio (PU/PA $=20: 80$ to $80: 20$ ) were prepared, and the damping and mechanical properties of these materials were studied. The damping of polyurethane soft phase was increased and shifted to lower temperature with increased content of PA vitreous phase. The mechanical properties were improved with increasing PA contents. The results show that PA and the polyurethane hard segment interaction play a special role in chain interpenetration density and its magnitude is revealed by the decreased dispersed domain size observed by scanning electron microscopy (SEM) and increased loss area as measured by dynamic mechanical thermal analysis (DMTA). When the weight ratio of PU/PA was 40:60, the resulting SIN materials possessed better damping properties, independent of $\mathbf{X}$ concentration.
\end{abstract}

Keywords: morphology, SINs, damping, PU/PA

\section{Introduction}

The damping behavior of polymeric materials has received increased attention from the scientific community due to its increased technological importance in the development of materials for application as coating, cushioning, structure frame, parts connector and others. Higher damping is associated to mechanical stability, thermal and sound isolation, just to cite some consequences, and can provide more comfortable environment.

Damping is the most sensitive indicator of all kinds of molecular motions displayed by a polymer in solid state and can be correlated to many transitions, relaxation processes, structural heterogeneities, and to the morphology of multiphase and crosslinked systems ${ }^{1}$.

Although most of published literature ${ }^{2-11}$ interpret the $\tan \delta$ intensity and its temperature spread in a dynamic-mechanical analysis as the damping capacity, this interpretation has received some criticism and the application of the

e-mail: wangshui@usp.br

Trabalho apresentado no $14^{\circ}$ CBECIMAT , Águas de São Pedro,

Dezembro 2000 integration of the area under the linear loss modulus in function of temperature curves has been suggested as a quantitative measurement of the damping capacity of the material by many authors ${ }^{7-11}$, supported by the fact that the loss modulus E" is directly proportional to the heat dissipated per cycle of dynamic deformation.

Interpenetrating polymer network (IPN) systems are known to introduce forced polymeric interaction between immiscible polymers, that are then able to present high connectivity among the phases, and also allowing the formation of fine, controllable and stable dispersed phase. IPN's compositions and synthesis can be designed in such a way that interaction forces and volume of interface between phases are maximized in order to achieve the highest damping.

Many researchers have studied the damping behavior of polymeric IPN's and it has been shown to be dependent on intensity of specific interaction ${ }^{4,10-11}$, crosslinking density $^{2-9}$, morphology or phase domain size $e^{2,4,8,9-11}$ and com- 
binations of them ${ }^{2,10}$. Specific interactions among non-miscible dissimilar components tend to increase damping as it contributes to increase the cohesiveness and the connectivity between phase separated components, while the intramolecular crosslinking density increases the cohesiveness of each phase and its influence on the damping depends on the morphology of the resultant system. Hence, the presence of crosslinking bonds can limit the chain segmental motion and fine dispersed domain phase can be set by its actuation, and at the same time, also coarse dispersed phase can be formed after copious crosslinking bonds resulting in drastic reduction of intermolecular interaction. In all materials studied it has been proved to be essential to track its morphology, and in heterogeneous polymeric system it has been noted that finer dispersed phase meant higher damping, as an expected result of the increase in damping by the interface of the immiscible system.

The use of hydroxyl-terminated polybutadiene (HTPB) as the flexible polyol component of polyurethane in IPN's is not usual, although its physical and chemical properties toward fillers, acidic and basic environments, its flexibility at low temperatures and its dielectric resistance are noteworthy. Besides that, its hydrocarbon structure contributes to form an immiscible phase in most of urethane/acrylate IPN systems, usually much polar ones.

The phenomenon of phase separation in IPN's is governed by polymer components interactions and the kinetic of its formation process ${ }^{2-12}$. It is well known that a simultaneous interpenetrating network (SIN) formation provides the best intersegmental contact for a given composition by reaching simultaneously the gel point of the two mechanistically independent polymerization reactions resulting in an interlocked polymeric system. The shift and/or broadening of individual thermal transition can be taken as an indicative of the degree of miscibility and/or dispersity of the phases.

In this paper a series of segmented polyurethanes based in different proportions of hydroxyl terminated polybutadiene as the soft segment and tolylene diisocyanate (TDI) and di-isopropyl-N-aniline (DHPA) as the hard segment (X) were studied in composition with a polyacrylate based on poly(methyl methacrylate) with a constant crosslinking density provided by ethylene glycol dimethacrylate. The polyurethane was crosslinked in the soft segment through the functionality of 2.2 of HTPB. The morphology of IPN's was analyzed as resultant of the interaction among PA and both phases of PU. We varied systematically the hard to soft segment ratio in the PU component, and for each specific PU composition a whole range of PU/PA IPN's was prepared, allowing us to explore the interactions of the acrylic phase with PU's soft and hard phases.

\section{Experimental}

\subsection{Materials}

Hydroxyl terminated polybutadiene (HTPB) from Petroflex (Brazil), $\mathrm{Mn}=2700$, number average functionality $\mathrm{fn}=2.2$ was dried at $100^{\circ} \mathrm{C}$ under $10 \mathrm{~mm} \mathrm{Hg}$ of pressure for $2 \mathrm{~h}$. Tolylene diisocyanate (TDI) from Bayer (Brazil), mixture of 2,4/2,6 isomers in a 80/20 ratio was distilled at $115^{\circ} \mathrm{C}$ under10 mm Hg. N,N-di(2-hydroxyisopropyl)aniline (DHPA) from Dow Chemical was dried at $100{ }^{\circ} \mathrm{C}$ under $10 \mathrm{~mm} \mathrm{Hg}$ of pressure for $2 \mathrm{~h}$. Methylmethacrylate (MMA) from Nitriflex (Brazil) was washed twice with 5\% aqueous $\mathrm{NaOH}$ followed by twice with distilled water, dried with $\mathrm{CaCl}_{2}$, filtered and kept over magnesium sulfate at low temperature and distilled before use at $100-101{ }^{\circ} \mathrm{C}$. Ethyleneglycol dimethacrylate (EGDMA) from Aldrich was dried with $\mathrm{CaH}_{2}$ for $24 \mathrm{~h}$ and distilled at $110{ }^{\circ} \mathrm{C}$ under $10 \mathrm{~mm} \mathrm{Hg}$. Benzoyl peroxide from Peróxidos do Brasil was recrystalized from methanol under dry nitrogen.

\subsection{IPN preparation}

PU Prepolymers: In a $500 \mathrm{ml}$ kettle type reactor equipped with mechanical stirrer, the required amounts of HTPB and TDI were allowed to react for $2 \mathrm{~h}$ at $60{ }^{\circ} \mathrm{C}$. PMMA Prepolymers: This was prepared at the same time as the PU prepolymer. MMA monomer, EGDMA (2\%) and benzoyl peroxide $(0.5 \% \mathrm{w} / \mathrm{w})$ were mixed, heated to $63{ }^{\circ} \mathrm{C}$ and then maintained for 30 minutes. IPNs: The PMMA prepolymer was added to the PU prepolymer and after complete homogenization, the PU chain extender DHPA (containing a drop of the catalyst, dibutyl tin laurate) was added. The material was poured into a vertical glass mold $\left(15 \times 20 \times 0.2 \mathrm{~cm}^{3}\right)$ and cured at $55^{\circ} \mathrm{C}, 80^{\circ} \mathrm{C}$ and $100{ }^{\circ} \mathrm{C}$, during $48 \mathrm{~h}, 48 \mathrm{~h}$ and $24 \mathrm{~h}$, respectively. IPN's of PU and poly(methylmethacrylate-co-ethyleneglycol dimethacrylate) (PA) were prepared having PU/PA ratios of 100/0, 80/20, 60/40, 50/50, 40/60, 20/80 and 0/100.

\subsection{Morphological characterization}

A JEOL CF-35 scanning electron microscope was used to perform textural characterization of fractured surfaces of the samples. Each one was fractured cryogenically and submitted to gold sputtering before analysis. Magnifications of $300 \mathrm{X}$ to $20000 \mathrm{X}$ were applied to each sample in order to estimate the domain size. 


\subsection{Dynamic mechanical thermal analysis (DMTA)}

A Rheometrics Scientific DMTA IV was used to perform bending tests with single cantilever fixtures. Each sample was cut to a small rectangular bar within the following range of dimensions: length of 23 to $26 \mathrm{~mm}( \pm 0.05)$, width of 4 to $8 \mathrm{~mm}( \pm 0.05)$, and thickness of 1.5 to $3.0 \mathrm{~mm}$ $( \pm 0.05)$. A strain limit of $0.02 \%$ and a frequency of $10 \mathrm{~Hz}$ were applied in the temperature range from $-90^{\circ} \mathrm{C}$ to $170^{\circ} \mathrm{C}$

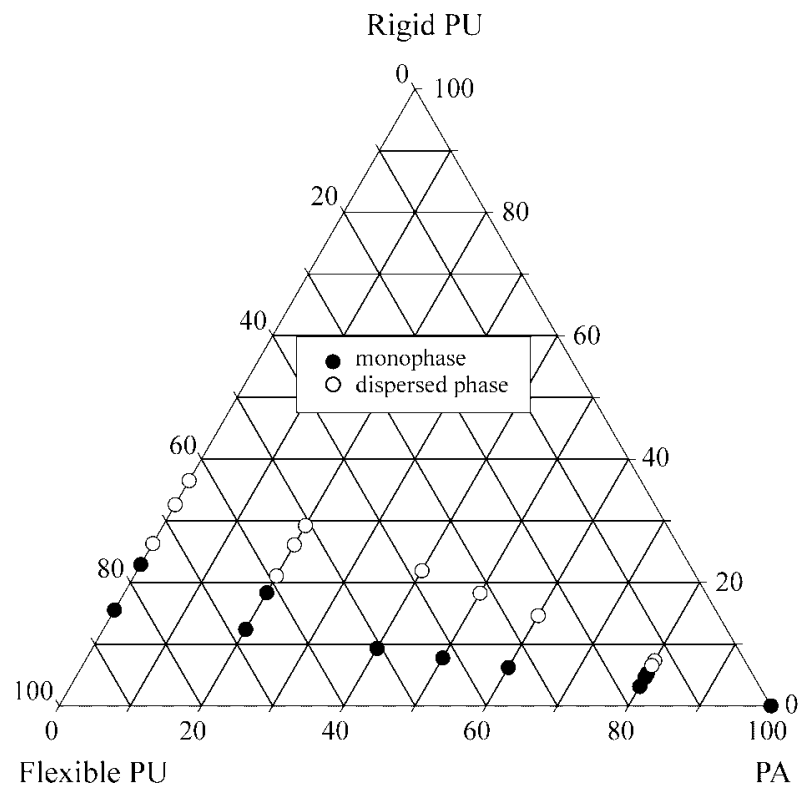

Figure 1. Three-component phase diagram of SIN's as observed by SEM. Rigid PU: PU's hard segment, Flexible PU: PU's HTPB and PA: Crosslinked Poly(methyl methacrylate). at a heating rate of $2{ }^{\circ} \mathrm{C} / \mathrm{min}$. The area under the linear loss area versus temperature was determined by integrating the area limited by a straight baseline traced between the inflexion points before and after the peak.

\section{Results and Discussion}

Polyurethane/PMMA SINs were prepared with various hard segments contents $(\mathbf{X})$ and wide range of PU/PA ratios (20/80 to 80/20). Details of preparation have been published elsewhere ${ }^{13}$. The composition of some studied SIN's materials is shown in Table 1.

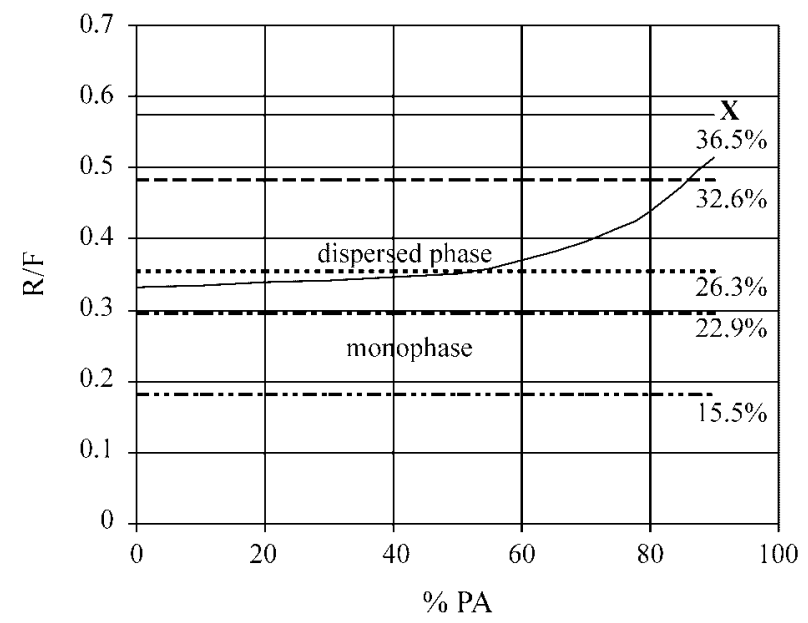

Figure 2. Phase diagram representing boundary curve between monophasic and non-monophasic systems as observed by SEM. Horizontal lines refers to series of SIN's with PU's containing several concentrations of hard segment $\mathrm{X}$, and $\mathrm{R} / \mathrm{F}$ refers to rigid segment to flexible segment ratio in PU component.

Table 1. Composition of SIN's.

\begin{tabular}{|c|c|c|c|c|}
\hline PU/PA & $\begin{array}{c}\mathbf{X} \\
(\%)\end{array}$ & $\begin{array}{c}\text { Flexible PU (F) } \\
(\%)\end{array}$ & $\begin{array}{c}\text { Rigid PU (R) } \\
(\%) \\
\end{array}$ & $\begin{array}{l}\text { PA } \\
(\%) \\
\end{array}$ \\
\hline $0 / 100$ & - & - & - & 100 \\
\hline $100 / 0$ & 36.5 & 63.5 & 36.5 & - \\
\hline $20 / 80$ & 36.5 & 12.7 & 7.3 & 80 \\
\hline $40 / 60$ & 36.5 & 25.4 & 14.6 & 60 \\
\hline $50 / 50$ & 36.5 & 31.75 & 18.25 & 50 \\
\hline $60 / 40$ & 36.5 & 38.1 & 21.9 & 40 \\
\hline $80 / 20$ & 36.5 & 50.8 & 29.2 & 20 \\
\hline $20 / 80$ & 15.5 & 16.9 & 3.1 & 80 \\
\hline $40 / 60$ & 15.5 & 33.8 & 6.2 & 60 \\
\hline $50 / 50$ & 15.5 & 42.25 & 7.75 & 50 \\
\hline $60 / 40$ & 15.5 & 50.7 & 9.3 & 40 \\
\hline $80 / 20$ & 15.5 & 67.6 & 12.4 & 20 \\
\hline
\end{tabular}



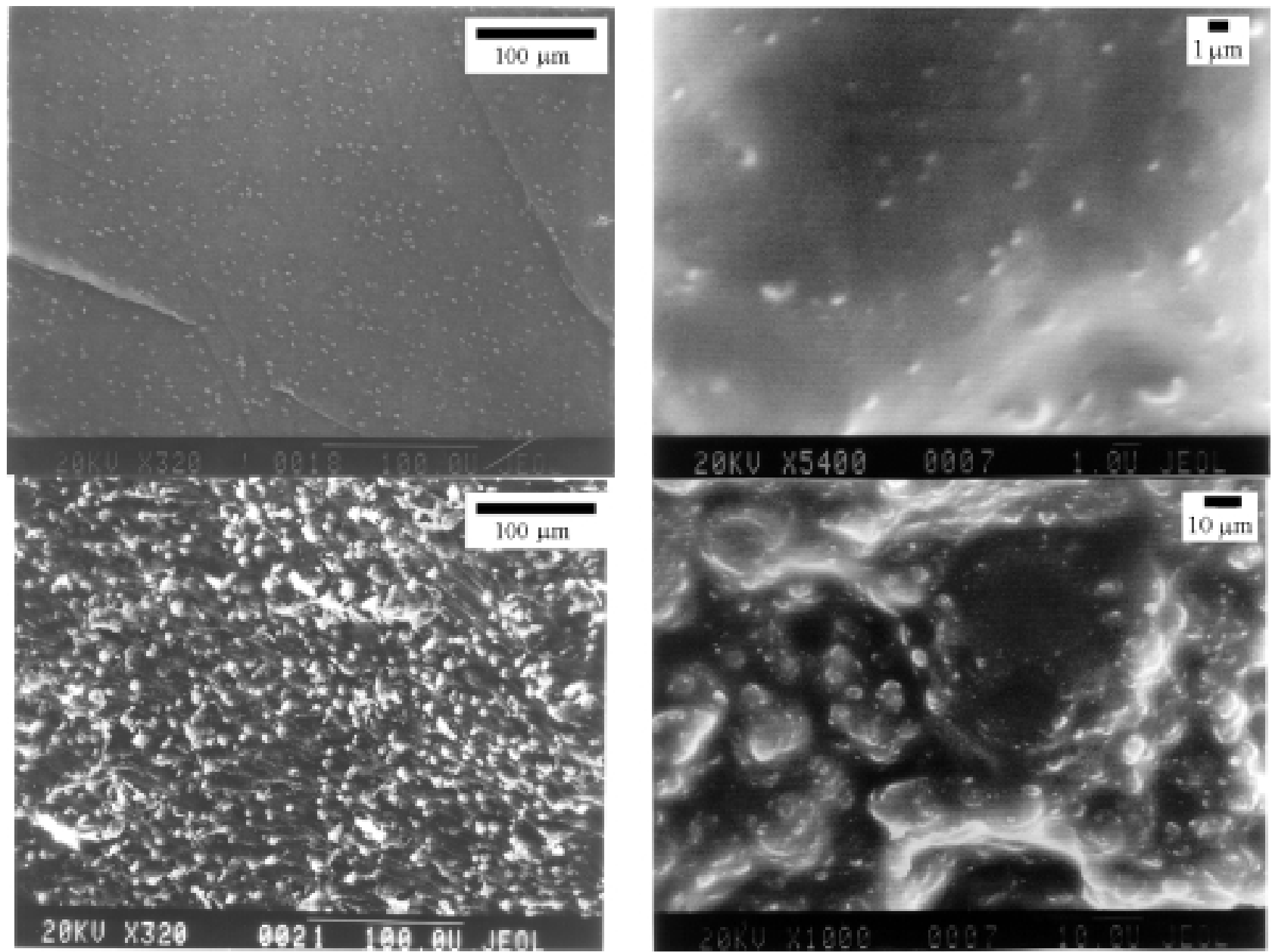

Figure 3. SEM of SIN's. From top to bottom; right, PU/PA = 20/80: (1) $\mathrm{X}=32.6 \%$ (5400X) and (2) $\mathrm{X}=36.5 \%$ (1000X); left, $\mathrm{PU} / \mathrm{PA}=80 / 20$ : (3) $X=32.6 \%$ (320X) and (4) $X=36.5 \%$ (320X).

Morphological examination by SEM allowed the construction of a three-component phase diagram (Fig. 1) where a boundary line can be drawn between systems with a dispersed phase and monophase systems ${ }^{14}$.

The observation limit by SEM analysis of these samples was $50 \mathrm{~nm}$. The non-monophasic systems have shown a wide range of domain sizes for the dispersed phase, and accordingly to that size, SIN's were transparent, translucent or opaque by visual observation. In the Fig. 2, the SIN's with different compositions in respect to the boundary line are represented, below the line are the monophasic systems and above the line the systems displayed a dispersed phase which domain size increases with the distance from the line to the top. The horizontal straight lines represent the series of SIN's with the various PU containing different concentration of hard segment $(\mathbf{X})$.
Some features of the SIN's can be observed in the SEM analysis in Fig. 3, and the overall observed results are in accordance to Fig. 2. For example, in Fig. 3, sample 1 (with $80 \%$ PA and $\mathbf{X}=32.6 \%)(0.2-0.5 \mu \mathrm{m})$ and sample 2 (with $80 \% \mathrm{PA}$ and $\mathbf{X}=36.5 \%)(2-5 \mu \mathrm{m})$ have a much finer structure compared to sample $\mathbf{3}$ (with $20 \% \mathrm{PA}$ and $\mathbf{X}=32.6 \%)(3 \mu \mathrm{m})$ and sample $\mathbf{4}$ (with $20 \% \mathrm{PA}$ and $\mathbf{X}=36.5 \%)(10-15 \mu \mathrm{m})$, respectively, as expected from graphic in Fig. 2.

In the polymeric systems containing higher concentration of PU hard segment (26.3\% and higher) finer dispersions were observed for SINs with PA content more than $50 \%$ of PA, vitreous matrix, indicating better compatibility than those observed for rubbery matrix SINs. The domain sizes of the observed dispersed phase were virtually the same up to $50 \%$ of PA, however, when PA is the matrix 
polymer, SIN's showed a decreasing dispersed phase domain size as PA amount is increased.

Although rubbery matrix SIN's presented coarser dispersed phase by SEM, the almost constant dispersed size domain can be seen as a sign of compatibility enhancement between PU and PA, as the increased amount of PA did not have an effect on the dispersed domain size and in the amount of dispersed phase. The inward shift of the PA thermal transition $(\tan \delta$ ) observed in these samples by DMTA is also an indication of that compatibilization process (Table 2).

The tensile properties of the SIN's have been discussed elsewhere ${ }^{13}$. The general behavior of these materials depends on PA content and on the hard segment content in the polyurethane (Fig. 4). Increasing PA content, a sharp increase of tensile strength and a consequent decrease in the elongation of rupture have been seen in the range from $40 \%$ to $50 \%$ of $\mathrm{PA}$, that was indicative of matrix inversion. Similar transitions were observed by DMTA.

Two series of SINs samples were characterized by DMTA (Table 2). Although some SIN's samples were homogeneous by SEM, all studied samples have proved to be immiscible or partially miscible by DMTA analysis and all of them have shown individual thermo-mechanical transition for the rubbery and vitreous phases, respectively.

Damping is the most sensitive indicator of all kinds of molecular motions displayed by a polymer in solid state. The loss modulus E" is directly proportional to the heat dissipated per cycle and the area under the linear loss modulus $v s$. temperature curves is a quantitative measurement of the damping behavior ${ }^{15}$ and can be correlated to

Table 2. Thermal transitions of the samples observed by DMTA.

\begin{tabular}{lccc}
\hline $\mathbf{X}$ content $\%$ & $\begin{array}{c}\text { Composition } \\
\text { PU/PA }\end{array}$ & \multicolumn{2}{c}{$\tan \boldsymbol{\delta}$ peak $(\boldsymbol{\alpha}$ - relaxations $)$} \\
\hline 0 & $0 / 100$ & & 150 \\
36.5 & $100 / 0$ & -52 & 56 \\
15.5 & $20 / 80$ & -63 & 154 \\
15.5 & $40 / 60$ & -51 & 164 \\
15.5 & $50 / 50$ & -50 & 65 \\
15.5 & $60 / 40$ & -45 & 29 \\
15.5 & $80 / 20$ & -49 & 17 \\
36.5 & $20 / 80$ & -61 & 142 \\
36.5 & $40 / 60$ & -58 & 150 \\
36.5 & $50 / 50$ & -60 & 115 \\
36.5 & $60 / 40$ & -55 & 111 \\
36.5 & $80 / 20$ & -57 & 81 \\
\hline
\end{tabular}

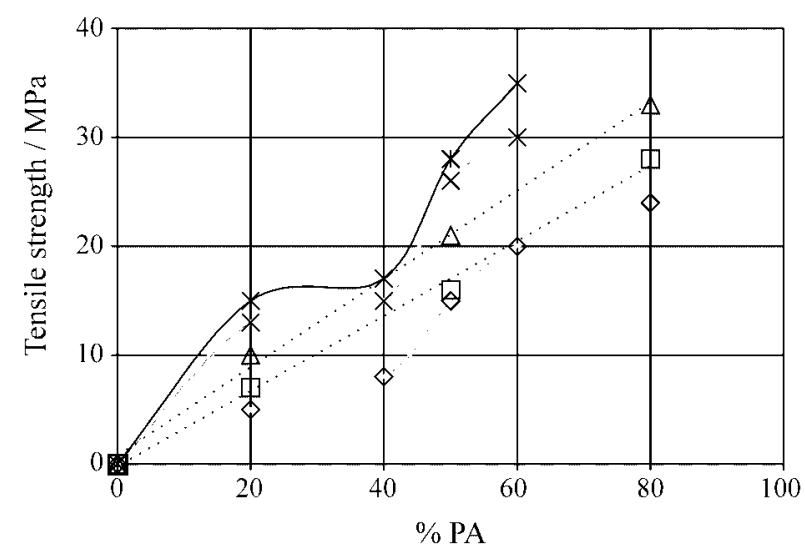

Figure 4. Variation of tensile strength of IPN's as a function of PA content and $X .(*) X=36.5 \%$; (x) $X=32.6 \% ;(\Delta) X=26.3 \%$; $(\diamond) X=22.9 \%$; and ( $\square) \mathrm{X}=15.5 \%$.

many transitions, relaxation processes, structural heterogeneities, and the morphology of multiphase and crosslinked systems. The linear loss modulus areas of the rubbery phase were determined (Fig. 5) and a correlation to the SIN composition was plotted (Fig. 6). Both series presented a maximum around $\mathrm{PA}=60 \%$, and it is indicative of higher compatibility in the polymeric system.

The increment in the damping observed by the linear loss area of PU soft segment at higher concentration of PA in the SIN's can be attributed to a higher cohesiveness reached by SIN's when PU's hard segments presented the most intimate mixing with the PA component. This can be explained by the preferential mixing of the hard segments with PA compared to the interaction pairs, PU flexible segments-PU rigid segments and PU flexible segments-PA component, due to the rise of specific secondary dipolar interactions and to the segmental molecular interlocking caused by the crosslinking of the PA component, during the early stages of SIN's formation. Furthermore, it can be observed that the area under the loss modulus versus temperature curve is not a linear function of the soft segments concentration in the SIN's (Fig. 7), but it is rather the result of the synergism among the three components within each SIN sample, and dependent on the connectivity and continuity of phases, so lowest damping areas have been observed for the SIN's with $12.7 \%$ of flexible PU-7.3\% of rigid PU-80\% PA and 20\% PA-67.6\% of flexible PU-12.4\% of rigid PU, when the minor component presented lack of continuity.

\section{Conclusion}

Simultaneous interpenetrating polymer network systems comprised by crosslinked poly(methyl methacrylate) and crosslinked polyurethane based on hydroxyl termi- 

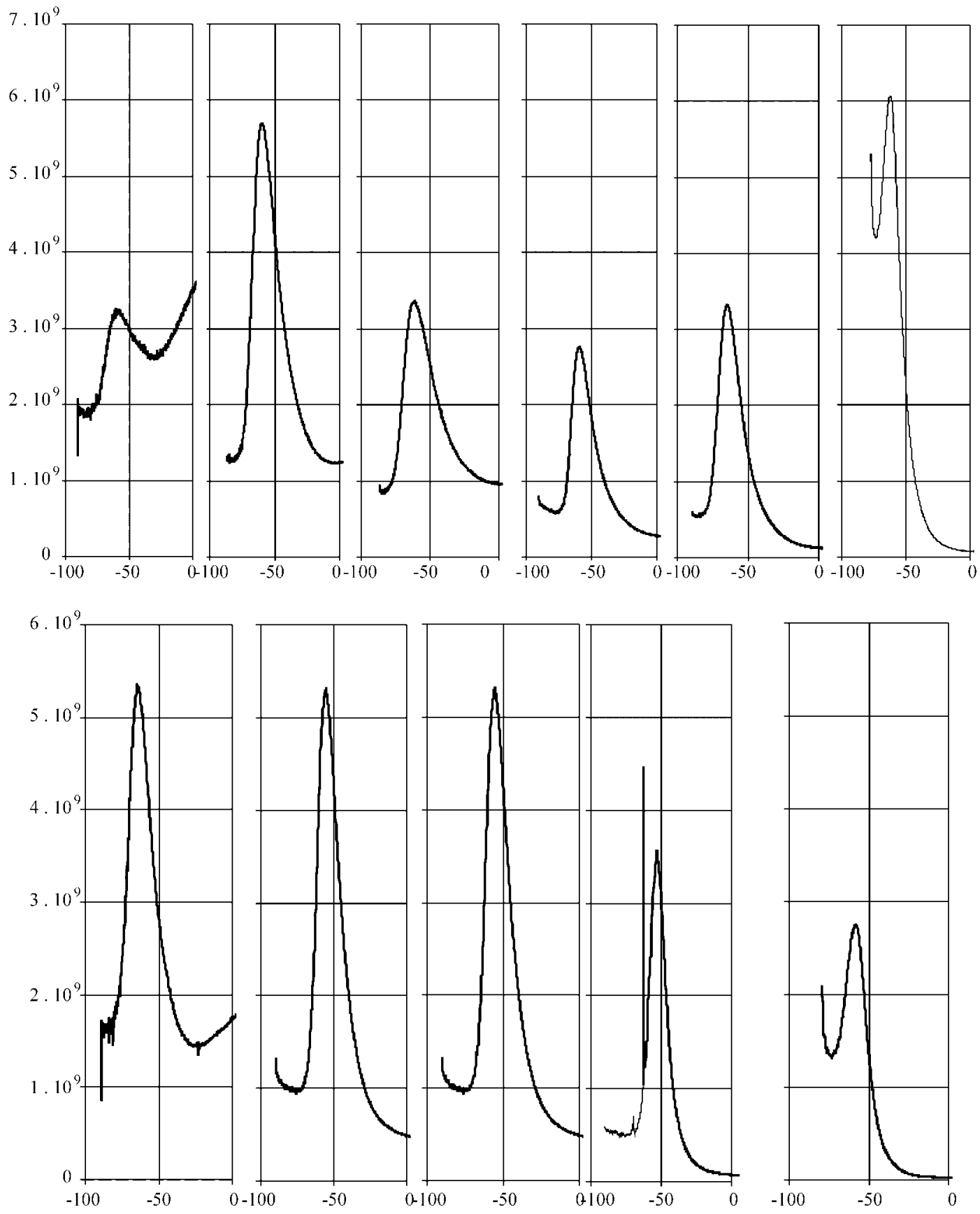

Figure 5. Linear loss modulus in function of temperature for SIN's samples. Top (X=36.5\%), from left to right, PU/PA ratio: 20/80; 40/60; 50/50; 60/40; 80/20; 100/0. Bottom (X = 15.5\%), from left to right, PU/PA ratio: 20/80; 40/60; 50/50; 60/40; 80/20.

nated polybutadiene have been obtained with a wide range of composition. The morphology of each sample was analyzed by SEM and DMTA, along with its mechanical and dynamic-mechanical properties, and the results were interpreted as a consequence of the interactions present in this ternary system. The crosslinking of the PA vitreous phase and the preferential specific interaction between PA com- ponent and the hard segments of PU component are responsible for the improvement of physical properties. SIN's samples containing $60 \%$ of PA component, independent of $\mathbf{X}$ content, presented a clear synergism in these systems and a maximum of damping was observed in conjunction with a finer dispersed phase. The damping maximization is attributed to a higher strength of interaction between 


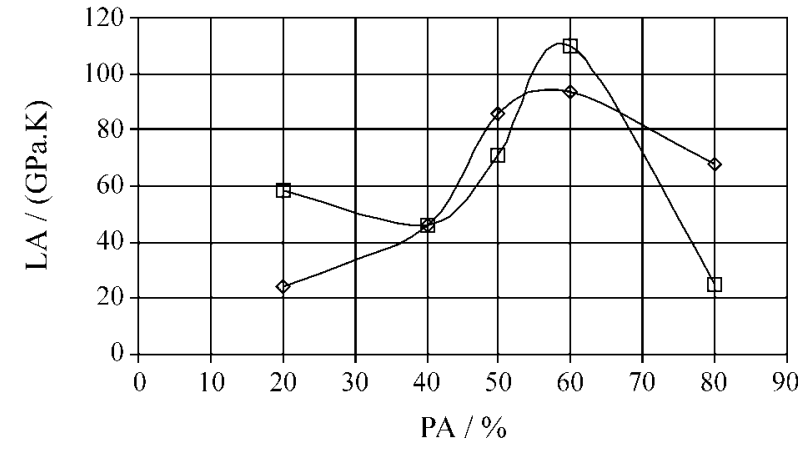

Figure 6. Linear loss modulus area in function of PA content. $X=36.5 \%$ and $(\diamond) X=15.5 \%$.

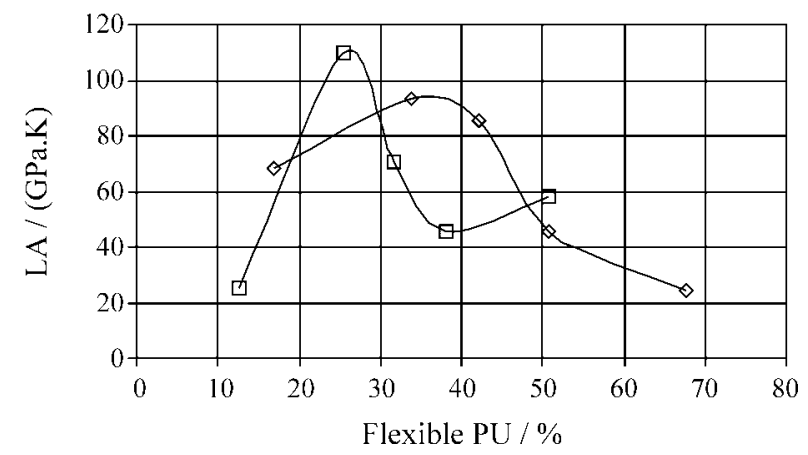

Figure 7. Linear loss modulus area in function of PU flexible segments content. ( $\square) \mathrm{X}=36.5 \%$ and $(\diamond) \mathrm{X}=15.5 \%$.

phases, and it is consequence of phase's interfacial cohesiveness and increased interface volume, or reduced dispersed particle sizes.

\section{Acknowledgment}

Financial support by Brazilian Agency CNPq is fully acknowledged. S.H.W. thanks FAPESP (99/01783-0) for financial support.

\section{References}

1.Nielsen, L.E.; Landel, R.F. Mechanical Properties of Polymers and Composites, 2nd edition, Marcel Dekker, Inc, New York, p. 131-232, 1994.

2.Kim, K.R.; An, J.H.; Cho, K.W.; Park, C.E. J. Appl. Polym. Sci., v. 47, p. 305-322, 1993.

3.Peng, W.; Li, S. J. Appl. Polym. Sci., v. 58, p. 967-971, 1995.

4. Yu, X.; Gao, G.; Wang, J.; Li, F.; Tang, X. Polym. Int., v. 48, p. 805-810, 1999.

5.Patri, M.; Samui, A.; Deb, P.C. J.Appl. Polym. Sci., v. 48, p. 1709-1716, 1993.

6. Tung, C.J.; Hsu, T.C.J. J. Appl. Polym. Sci., v. 46, p. 1759-1773, 1992.

7.Fay, J.J.; Murphy, C.J.; Thomas, D.A.; Sperling, L.H. Polym. Eng. Sci., v. 31, p. 1731-1741, 1991.

8. Chen, Q.; Ge, H.; Chen, D.; He, M; Yu, X. J. Appl. Polym. Sci., v. 54, p. 1191-1197, 1994.

9. Hourston, D; Schäfer, F-U; J. Appl. Polym. Sci., v. 62, p. 2025-2037, 1996.

10.Hu, R.; Dimonie, V.L.; El-Aasser, M.S.; Pearson, R.A.; Hiltner, A.; Mylonakis, S.G.; Sperling, L.H. J. Polym. Sci. B: Polym Phys., v. 35, p. 1501-1514, 1997.

11.Chern, Y.C.; Tseng, S.M.; Hsieh, K.H.; J. Appl. Polym. Sci., v. 74, p. 335-328, 1999.

12.Xu, M.; MacKnight, W.J.; Chen, C.H.Y.; Thomas, E.L. Polymer, v. 28, p. 2183-2189, 1987.

13. Wang, S.H.; Zawadzki, S.; Akcelrud, L.; J. Polym. Sci. B: Polym Phys., v. 38, p. 2861-2872, 2000.

14. Wang, S.H.; Zawadzki, S.; Akcelrud, L. Mat. Sci. Forum, v. 282-283, p. 289-294, 1998.

15. Chang, M.C.O.; Thomas, D.A.; Sperling, L.H. J. Polym. Sci.: Part B; Polym. Phys., v. 26, p. 1627-1640, 1988.

FAPESP helped in meeting the publication costs of this article 